\title{
In-vitro Activity of Three Brands of Ceftriaxone against different Clinical Isolates
}

\author{
Thapa B, ${ }^{1}$ Mahat $\mathrm{K}^{2}$ \\ 'Department of Microbiology, Kathmandu Medical College, 2Mahidol University Alumni Association Nepal, Kathmandu, Nepal.
}

\begin{abstract}
Introduction: Ceftriaxone is an extended spectrum cephalosporin that has been used for decades for combating infections caused by wide array of pathogens and prescription of antibiotic is in favor of specific brands without realizing the potency of the brand. The in-vitro activity of three brands of ceftriaxone and various antibiotics against clinical isolates is studied.
\end{abstract}

Methods: This comparative study was carried in Kathmandu Medical College Teaching Hospital (KMCTH), Basic Science Complex, Duwakot, Bhaktapur in 2009. Thirteen clinical isolates isolated from the specimens processed in the Microbiology Laboratory at KMCTH were used. Minimum inhibitory concentration (MIC) of three brands of ceftriaxone (A, B, and C) was determined by agar dilution and antibiotic resistance patterns were deduced by disc diffusion test.

Results: MIC for three brands of ceftriaxone ranged from $<0.25$ to $>256 \mathrm{mg} / \mathrm{L}$. The MIC for brands A and C of ceftriaxone were consistent for all isolates while for brand B, MIC was higher by at least two fold suggesting this brand had less in-vitro activity against isolates tested. All isolates were multi-drug resistant. Ceftriaxone resistant isolates $(n=6)$ were simultaneously resistant to various antibiotics tested. Imipenem and amino glycosides were sensitive to the isolates studied.

Conclusions: Different brands of ceftriaxone are available in Nepal and imprudent use of less potent antibiotics should be controlled to stop the emergence and spread of multi-drug resistant pathogens and to prevent undue economic burden to the patient and the country.

Keywords: agar dilution, ceftriaxone brands, multi-drug resistant

\section{INTRODUCTION}

Ceftriaxone is an injectable antibiotic, $90 \%$ protein bound, has a prolong half life of 5.8 hours, good penetration to cerebro spinal fluid (CSF) and has been used for treating meningitis. ${ }^{1}$ It has also been used for treating typhoid and combating various infections, bacteremia and septicemia in Nepal and abroad. ${ }^{2-5}$ It is also commonly used in intensive care units of Nepal. ${ }^{5}$ Despite its success, ceftriaxone resistant strains of Enterobacteriaceae and Staphylococcus aureus have emerged. ${ }^{5-7}$
Ceftriaxone is imported in Nepal and the success of the treatment relies on correct identification of the pathogen, appropriate antibiotic and dose, duration, and most importantly potency. Different brands of ceftriaxone are available in the market and prescription of one brand primarily depends upon the favor of the physician involved in the treatment process giving little attention to the potency. Hence, we have determined

\author{
Correspondence: \\ Dr. Badri Thapa \\ Department of Microbiology \\ Kathmandu Medical College, Kathmandu, Nepal. \\ E-mail: badri_bishal@yahoo.com \\ Phone: 977-9841220108
}


Thapa et al. In-vitro Activity of Three Brands of Ceftriaxone Against Different Clinical Isolates

the in-vitro antimicrobial activity of three brands of ceftriaxone against the clinical isolates and studied their antibiotic resistance patter.

\section{METHODS}

A comparative study was carried out in Department of Microbiology, KMCTH, Duwakot from October to December 2009. Thirteen clinical isolates consisting of Escherichia coli $(\mathrm{n}=8)$, Klebsiella spp. $(\mathrm{n}=3)$, Proteus spp. $(n=1)$, and $S$. aureus $(n=1)$ were isolated using standard procedures from different specimens (urine, pus, sputum, and endotracheal tube aspirate) at Microbiology Laboratory, KMCTH, Sinamangal, Nepal.

Three brands of ceftriaxone powder for injection was purchased from a commercial source and were blinded as $A, B$, and C. MIC ( $\mathrm{mg} / \mathrm{L})$ to three brands of ceftriaxone was determined by agar dilution as recommended by CLSI. ${ }^{8}$ Briefly, the stock concentrations of each brand of ceftriaxone were prepared as previously described. ${ }^{9}$ Ceftriaxone solution was added to the molten Muller Hinton agar (Himedia, India) to provide two fold serial dilutions ranging from 0.25 to $256 \mathrm{mg} / \mathrm{L}$. Few pinpoint colonies of overnight grown bacteria were suspended in peptone water to reach the turbidity of 0.5 McFarland standard $\left(\mathrm{BaSO}_{4}\right.$ turbidity standard). ${ }^{9}$ The $0.001 \mathrm{ml}$ inoculating loop was used to deliver $10^{4}$ colony forming unit $(\mathrm{cfu}) / \mathrm{spot}$ of bacteria into the agar plate containing the ceftriaxone. The plates were incubated at $35^{\circ} \mathrm{C}$ for 16 to 20 hours. The growth of a single colony or a haze was not considered. The lowest concentration of antibiotic that showed no bacterial growth was considered as MIC. E. coli ATCC 25922 and S. aureus ATCC 25923 were used as a quality control strains.

Antibiotic susceptibility test for the isolates was performed following CLSI guidelines. ${ }^{8}$ The antibiotic discs ( $\mu \mathrm{g} / \mathrm{disc}$ ) used were; Amoxycillin (10), AmoxycillinClavulenic acid (20/10), Piperacillin (100), TrimethoprimSulphamethoxazole (25), Ciprofloxacin (5), Norfloxacin (10), Gentamicin (30), Netilmicin (30), Kanamicin (30), Cefoxitin (30), Ceftriaxone (30), Ceftazidime (30), Cefuroxime (30), Cephazolin (30), Cefpodoxime (10), and Imipenem (10). All antibiotic discs were purchased from Himedia Pvt. Ltd, India except cefoxitin and cephzolin which were purchased from Oxoid, UK.

E. coli ATCC 25922 and S. aureus ATCC 25923 were used as quality control strains.

\section{RESULTS}

The in-vitro activity of three brands of commonly used ceftriaxone was studied by determining MIC by agar dilution. The result showed that two brands (A and $C$ ) had consistent in-vitro activity against all the isolates. MIC for these two brands ranged from $<0.25$ to $>256 \mathrm{mg} / \mathrm{L}$ while brand $\mathrm{B}$ was relatively less active and the MIC was higher by at least 2 fold for some of the isolates (Table 1). MIC obtained for the control strains were within the acceptable limits and all brands had MIC less than $0.25 \mathrm{mg} / \mathrm{L}$. The zone of inhibition obtained by disc diffusion test correlated well with the MIC obtained by agar dilution.

Table 1. Antibiotic resistance pattern and MIC of three brands of ceftriaxone against test isolates

\begin{tabular}{|c|c|c|c|c|c|c|}
\hline \multirow{2}{*}{ Isolates } & \multirow{2}{*}{ Isolate no. } & \multirow{2}{*}{ Resistant to, DDT } & \multirow{2}{*}{ Break point MIC } & \multicolumn{3}{|c|}{ MIC (mg/L) } \\
\hline & & & & A & B & C \\
\hline \multirow[t]{8}{*}{ E. coli } & EC1010 & $\mathrm{A}, \mathrm{PC}, \mathrm{CU}, \mathrm{CO}$ & $\leq 8 \mathrm{~S} \geq 64 \mathrm{R}$ & $<0.25$ & $<0.25$ & $<0.25$ \\
\hline & EC1013 & $\begin{array}{l}\mathrm{A}, \mathrm{AC}, \mathrm{PC}, \mathrm{Cl}, \mathrm{CA}, \mathrm{CU}, \mathrm{KZ}, \mathrm{CEP}, \mathrm{FOX}, \mathrm{CF}, \mathrm{NX} \\
\mathrm{K}, \mathrm{NT}, \mathrm{CO}\end{array}$ & $\leq 8 \mathrm{~S} \geq 64 \mathrm{R}$ & 128 & 256 & 128 \\
\hline & EC1019 & $\mathrm{A}, \mathrm{AC}, \mathrm{PC}, \mathrm{CA}, \mathrm{CU}, \mathrm{CF}, \mathrm{NX}, \mathrm{G}, \mathrm{K}, \mathrm{CO}$ & $\leq 8 \mathrm{~S} \geq 64 \mathrm{R}$ & $<0.25$ & $<0.25$ & $<0.25$ \\
\hline & EC1020 & $\mathrm{A}, \mathrm{PC}, \mathrm{CU}, \mathrm{CO}$ & $\leq 8 \mathrm{~S} \geq 64 \mathrm{R}$ & $<0.25$ & 1 & $<0.25$ \\
\hline & EC1032 & $\mathrm{A}, \mathrm{PC}, \mathrm{Cl}, \mathrm{CA}, \mathrm{CU}, \mathrm{KZ}, \mathrm{CEP}, \mathrm{NX}$ & $\leq 8 \mathrm{~S} \geq 64 \mathrm{R}$ & 64 & 64 & 64 \\
\hline & EC10320 & $\mathrm{A}, \mathrm{PC}, \mathrm{CA}, \mathrm{KZ}, \mathrm{CO}$ & $\leq 8 S \geq 64 R$ & $<0.25$ & $<0.25$ & $<0.25$ \\
\hline & EC10165 & $\mathrm{A}, \mathrm{AC}, \mathrm{PC}, \mathrm{Cl}, \mathrm{CA}, \mathrm{CU}, \mathrm{KZ}, \mathrm{CEP}, \mathrm{CF}, \mathrm{NX}, \mathrm{CO}$ & $\leq 8 \mathrm{~S} \geq 64 \mathrm{R}$ & 64 & 128 & 64 \\
\hline & EC10159 & $\mathrm{A}, \mathrm{PC}, \mathrm{CU}, \mathrm{NT}$ & $\leq 8 \mathrm{~S} \geq 64 \mathrm{R}$ & $<0.25$ & $<0.25$ & $<0.25$ \\
\hline \multirow[t]{3}{*}{ Klebsiella spp. } & KS1026 & $\begin{array}{l}\mathrm{A}, \mathrm{AC}, \mathrm{Cl}, \mathrm{CA}, \mathrm{CU}, \mathrm{KZ}, \mathrm{CEP}, \mathrm{FOX}, \mathrm{I}, \mathrm{CF}, \mathrm{NX}, \mathrm{G}, \\
\mathrm{K}, \mathrm{NT}, \mathrm{CO}\end{array}$ & $\leq 8 \mathrm{~S} \geq 64 \mathrm{R}$ & $>256$ & $>256$ & $>256$ \\
\hline & KS1028 & $\mathrm{A}, \mathrm{AC}, \mathrm{PC}, \mathrm{Cl}, \mathrm{CA}, \mathrm{CU}, \mathrm{KZ}$ & $\leq 8 \mathrm{~S} \geq 64 \mathrm{R}$ & $<0.25$ & $<0.25$ & $<0.25$ \\
\hline & KS1035 & $\mathrm{A}, \mathrm{AC}, \mathrm{PC}, \mathrm{Cl}, \mathrm{CA}, \mathrm{CU}, \mathrm{KZ}, \mathrm{CEP}, \mathrm{FOX}, \mathrm{NX}$ & $\leq 8 \mathrm{~S} \geq 64 \mathrm{R}$ & $>256$ & $>256$ & $>256$ \\
\hline Proteus spp. & PS1070 & $\mathrm{PC}, \mathrm{Cl}, \mathrm{CA}, \mathrm{CU}, \mathrm{KZ}, \mathrm{CEP}, \mathrm{CF}, \mathrm{NX}$ & $\leq 8 \mathrm{~S} \geq 64 \mathrm{R}$ & 64 & 128 & 64 \\
\hline S. aureus & SA1029 & $\mathrm{A}, \mathrm{PC}, \mathrm{CA}, \mathrm{CO}$ & $\leq 8 \mathrm{~S} \geq 64 \mathrm{R}$ & $<0.25$ & 2 & $<0.25$ \\
\hline
\end{tabular}

DDT, Disc Diffusion Test; A, B and C, Three brands of ceftriaxone; S, Sentsitive; R, Resistant; A, Amoxycillin; AC, Amoxycillin + Clavulenic Acid; PC, Piperacillin; Cl, Ceftriaxone; CA, ceftazidime, CU, Cefuroxime, KZ, Cephalothin; CEP, Cefpodoxime; FOX, Cefoxitin, I, Imipenem, CF, Ciprofloaxin; NX, Norfloxacin; G, Gentamicin; K, Kanamicin; NT, Netilmicin; and CO, Trimithoprim + Sulphamethoazole. 
Thapa et al. In-vitro Activity of Three Brands of Ceftriaxone Against Different Clinical Isolates

The disc diffusion test was performed on these isolates with 16 antibiotics representing different classes. All isolates were multi-drug resistant (Table 1). Ceftriaxone resistant isolates $(n=6)$ showed in-vitro resistance to numerous antibiotics ( 7 to 15 ) while most of them were susceptible to imipenem and amino glycosides.

\section{DISCUSSION}

Ceftriaxone, an extended spectrum cephalosporin is active against Gram positive and negative bacterial isolates and mostly for pathogens causing meningitis due to its high level in CSF. ${ }^{1}$ On light of emergence of multidrug resistant pathogens to penicillins, quinolones, tetracyclines, and narrow spectrum cephalosporins the role of extended spectrum cephalosporins is even more crucial. The effective treatment relies on several factors and most importantly the correct antibiotic and potency of the active drug.

We determined the in-vitro activity of three different brands of commercially available cefriaxone. The brand $B$ had lower in-vitro activity than its competitor brands $A$ and $C$. The MIC obtained for this brand was at least two fold higher than other brands for some isolates while for others all brands had MIC either $<0.25$ $\mathrm{mg} / \mathrm{L}$ or $>256 \mathrm{mg} / \mathrm{L}$. The ceftriaxone concentration tested ranged from $0.25 \mathrm{mg} / \mathrm{L}$ to $256 \mathrm{ml} / \mathrm{L}$ and since isolates had $\mathrm{MIC}<0.25 \mathrm{mg} / \mathrm{L}$ and $>256 \mathrm{mg} / \mathrm{L}$, the invitro activity on two extremes couldn't be known. The activity of brand B could have been known if ceftriaxone concentration $<0.25$ or $>256 \mathrm{mg} / \mathrm{L}$ were tested. For an isolate EC1032, MIC was $64 \mathrm{mg} / \mathrm{L}$ for all brands and this couldn't be explained. Study comparing different brands of ceftriaxone is scare in literature and we could not compare our study with others.

Among 13 multidrug resistant clinical isolates studied 6 were resistant to ceftriaxone. Ceftriaxone resistant isolates were further resistant to numerous antibiotics leaving the choice for imipenem and aminoglycosides. Ceftriaxone resistant clinical strains are emerging worldwide. Although, ceftriaxone resistant E. coli and Klebsiella spp. are scarce in literaturers, ceftriaxone resistant Salmonella spp. has been rising in Nepal. ${ }^{7,10}$ The resistance to this antibiotic is also a global concern. ${ }^{6}$

Ceftriaxone resistance is conferred by the plasmid borne CTX-M, CMY-2, TEM and SHV extended spectrum -lactamase enzyme (ESBL) and plasmid and chromosomal borne AmpC ESBL and resistance can spread rapidly to the susceptible isolates through horizontal gene transfer. ${ }^{6,11,12}$ Molecular epidemiology of resistance genes conferring resistance to this antibiotic is mandatory to formulate treatment guidelines and to know the extent of resistance gene spread caused by indiscriminate use of less potent antibiotic.

\section{CONCLUSIONS}

Ceftriaxone is an antibiotic widely used in clinical practice and is imported in Nepal. Hence, concerned authority has to consider the cost implications to the patient, family and the country before endorsing less potent ceftriaxone brands in the country. Prudent and potent antibiotic use will help prevent emergence and spread of antibiotic resistant strains, which in turn will benefit the patient and Nation as a whole.

\section{REFERENCES}

1. Axelrod JL, Newton JC, Sarakhun C, et al. Ceftriaxone a new cephalosporin with aqueous humor levels effective against Enterobacteriaceae. Arch Ophthamol. 1985;103:71-2.

2. Acharya G, C Crevoisier, T Butler, et al. Pharmacokinetics of ceftriaxone in patients with typhoid fever. Antimicrob Agents Chemother. 1994;38:2415-8.

3. Smith MD, Duong NM, Hoa NTT, et al. Comparison of ofloxacin and ceftriaxone for short-course treatment of enteric fever. Antimicrob Agents Chemother. 1994;38:1716-20.

4. Sharma N, Koju R, Karmacharya B, et al. Typhoid fever in Dhulikhel Hospital, Nepal. Kathmandu Univ Med J. 2003;2:188-92.

5. Shankar PR, Partha P, Dubey AK, Mishra P, Deshpande VY. Intensive care unit drug utilization in a teaching hospital in Nepal. Kathamandu Univ Med J. 2005;3:130-7.

6. Goldstein FW, Péan Y, Rosato A, Gertner J, Gutmann L. Characterization of ceftriaxone-resistant Enterobacteriaceae: a multicenter study in 26 French Hospitals. J Antimicrob Chemother. 1993;32:595-603.

7. Neopane A, Singh SB, Bhatta R, Dhital B, Karki DB. Changing spectrum of antibiotic sensitivity in enteric fever. Kathamandu Univ Med J. 2008;6:12-5.

8. Clinical Laboratory Standards Institute. Performance Standards for Antimicrobial Susceptibility Testing. NCCLS document M100-S15, Fifteenth Informational Supplement. $25^{\text {th }}$ ed. USA: Clinical Laboratory Standards Institute. 2005.

9. Andrews JM. Determination of minimum inhibitory concentrations. J Antimicrob Chemother. 2001;48:5-16.

10. Malla S. Salmonella infection and antimicrobial resistance trend in Nepal. Meeting on typhoid fever vaccination in the Asia pacific region. Bangkok, Thailand: 2009.

11. Paul DF, Safranek TJ, Rupp ME, et al. Ceftriaxone-resistant salmonella infection acquired by a child from cattle. New Engl J Med. 2000;342:1242-9.

12. Yan JJ, Ko WC, Tsai SH, Wu HM, Jin YT, Wu JJ. Dissemination of CTX-M-3 and CMY-2 $\beta$-Lactamases among clinical isolates of Escherichia coli in Southern Taiwan. J Clin Microbiol. 2000;38:4320-25. 